\title{
Diagnóstico de SARS-CoV-2: Importancia de entender los métodos actuales
}

\section{Diagnosis of SARS-CoV-2: Importance of understanding current methods}

Luis Jaramillo-Valverde ${ }^{1,2, a \text { 巡 }}$

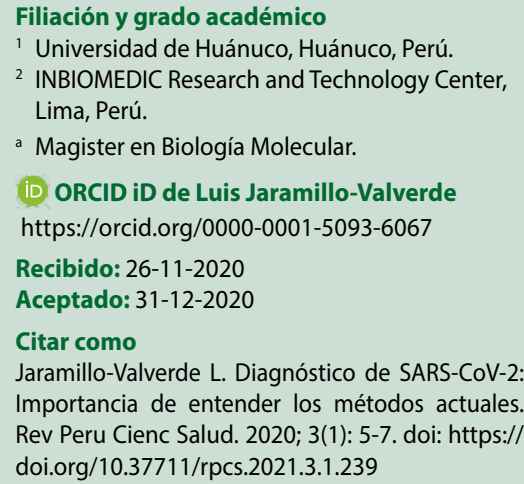

iD ORCID iD de Luis Jaramillo-Valverde https://orcid.org/0000-0001-5093-6067

Recibido: 26-11-2020

Aceptado: 31-12-2020

Citar como

Jaramillo-Valverde L. Diagnóstico de SARS-CoV-2 Importancia de entender los métodos actuales. Rev Peru Cienc Salud. 2020; 3(1): 5-7. doi: https:// doi.org/10.37711/rpcs.2021.3.1.239

Correspondencia

Luis Jaramillo-Valverde

luisjaramillovalverde@gmail.com
Actualmente, tanto en el Perú como en otros países, tenemos una gran oferta de pruebas disponibles para la identificación de individuos contagiados con la enfermedad de COVID-19; sin embargo, ¿conocemos cuáles son las ventajas y limitaciones de cada una ellas?

La gran cantidad de metodologías de pruebas disponibles para el diagnóstico de infección por SARS-CoV-2 ${ }^{(1,2)}$, así como la complejidad de la respuesta inmune humana nos lleva a la necesidad de conocer la indicación e interpretación adecuada de los resultados de las pruebas moleculares disponibles. Por consiguiente, las pruebas diagnósticas confirmatorias (presencia de SARS-CoV-2) solo deben estar basadas en la detección del ARN viral o antígeno viral. Debemos recordar que el secuenciamiento del primer genoma del coronavirus en enero del presente año ${ }^{(3)}$ hizo posible el diseño de múltiples metodologías para su diagnóstico y el desarrollo de vacunas candidatas. Es así que la gran cantidad de insumos, metodologías para el análisis molecular (amplificación de una secuencia específica del ARN viral) y detección de antígenos de superficie del virus han sido diseñadas para la detección oportuna y costo efectiva del SARS-CoV-2.

La prueba molecular RT-PCR (reacción en cadena de la polimerasa con transcriptasa inversa) en tiempo real para la detección de SARSCoV-2, a partir de muestras tomadas con un hisopado nasofaríngeo, es actualmente el gold standard para el diagnóstico de COVID-19 en la fase aguda ${ }^{(1,2)}$.

Por ejemplo, en individuos sintomáticos el ARN (ácido ribonucleico) viral puede detectarse desde el día uno o desde la primera semana del inicio de los síntomas; sin embargo, debemos tomar en cuenta que la positividad de la prueba para detectar este ARN viral disminuye a partir de las tres semanas de la infección ${ }^{(4)}$. El no tener claro lo anterior podría causar resultados falsos negativos debido al momento inadecuado de la toma de muestras. Por otro lado, la especificidad de casi el $100 \%$ de esta prueba se debe a que se basa en la identificación de secuencias propias del genoma del SARS-CoV-2 ${ }^{(4)}$. En el contexto de una pandemia, en los pacientes sintomáticos con resultado RTPCR negativo se debe considerar repetir la prueba RT-PCR además de investigar otras infecciones respiratorias; mientras que en caso de existir sintomatología y una prueba negativa se debería evaluar el uso de un panel de virus respiratorios ${ }^{(5)}$. Por otro lado, en personas asintomáticas que han tenido contacto con un caso confirmado de COVID- 19 es recomendable realizarse la RT-PCR después de 5 días del contacto ${ }^{(4)}$.

Una información muy útil en el RT-PCR son los ciclos de amplificación (Cycles threshold, $C t$ ), que en pacientes positivos con una alta carga 
viral revelan menor $\mathrm{Ct}$ que en pacientes positivos con menor carga viral, este concepto aunado a la información clínica son, por lo tanto, de mucha utilidad para la evaluación, seguimiento y pronóstico de los pacientes que han desarrollado la enfermedad ${ }^{(6)}$.

Una técnica molecular que reduce el tiempo y la complejidad en el diagnóstico es la amplificación isotérmica mediada por bucle (LAMP), la cual permite que las cadenas de ADN recién copiadas formen estructuras en bucle que pueden amplificarse mucho más rápidamente que en la RT-PCR; requiriendo solo una hora de amplificación, con niveles de sensibilidad y especificidad aceptables en comparación con la prueba Gold standard ${ }^{(7)}$. Una ventaja de LAMP es que requiere una logística más sencilla para su procesamiento y es más factible realizar un mayor número de pruebas en laboratorios de menor complejidad. Por otro lado, debemos reconocer algunas limitaciones en comparación con la RT-PCR en tiempo real, como es la presencia o ausencia de un control interno, el ratio de detección según el número de copias del virus, el no revelado de $C t$ y algunos aspectos adicionales que requieren de ajustes para lograr una máxima correlación con la técnica RT-PCR. Es por ello que, en pacientes que requieran hospitalización, se debe confirmar el diagnóstico mediante la realización de la prueba RTPCR en tiempo real. Teniendo en cuenta lo anterior, la técnica LAMP se recomienda para diagnóstico en personas consideradas casos sospechosos en áreas de alta positividad y ante la necesidad de incrementar el acceso a otras técnicas diagnósticas moleculares ${ }^{(8)}$.

Asimismo, es importante señalar que tanto la prueba molecular RT-PCR como LAMP requieren de personal entrenado para la toma de muestras $y$, su procesamiento previo a la inactivación de la muestra misma, exige disponer de cabinas de bioseguridad de nivel II. La adecuada toma de muestras (hisopado nasofaríngeo) resulta fundamental para minimizar la posibilidad de falsos negativos ${ }^{(9)}$.

Adicionalmente a los dos métodos moleculares descritos, en los últimos meses se están comercializando pruebas de diagnóstico rápido que detectan la presencia de proteínas virales (antígenos) del SARSCoV-2 en muestras de las vías respiratorias o saliva. Las pruebas determinan la presencia de los dominios S1 y S2 de la de la proteína $\mathrm{S}^{(10)}$. La mayoría de ellas, basadas en inmunoensayos de flujo lateral (LFI) que normalmente se realizan en 30 minutos, requieren altos niveles de bioseguridad. A diferencia de las pruebas moleculares RT-PCR y LAMP, la prueba de antígenos no amplifica el material genético que se pretende detectar, haciendo menos sensibles a las pruebas de antígenos ${ }^{(11)}$; además, podrían producirse resultados falsos positivos si los anticuerpos de la tira de la prueba reconocen antígenos de virus distintos del SARS-CoV-2, como en el caso de otros coronavirus humanos ${ }^{(12)}$.

Algunos estudios han comparado las pruebas de diagnóstico rápido con la RT-PCR en hisopados nasofaríngeos, obteniendo resultados variables (13-15). Las cargas virales más altas $(C t<25)$ están asociadas a mejores rendimientos de la prueba de antígenos. Esto permite prever que el rendimiento de la prueba será óptimo en torno a la aparición de los síntomas y en la fase inicial de la infección por el SARSCoV-2 (5to al 7mo día) ${ }^{(11)}$; sin embargo, para pacientes portadores con menor carga viral (la mayoría de ellos asintomáticos), el uso de la prueba de antígeno sería muy limitado ${ }^{(11,16)}$.

Debemos tomar en cuenta también la importancia de la recolección y preprocesamiento de muestras biológicas independientemente del método de diagnóstico; ya se ha reportado que los errores pre analíticos representan un $30 \%$ de los falsos negativos ${ }^{(17)}$. Por lo tanto, el tipo de muestra, la carga viral, la fase de la enfermedad, la recolección y el preprocesamiento de las muestras son factores que influyen en la sensibilidad del método de diagnóstico y deben combinarse adecuadamente para obtener resultados ideales. A pesar de estos desafíos, diversas herramientas de diagnóstico continuarán desempeñando un papel crítico y complementario en el manejo de las diversas etapas de la pandemia de la COVID-19.

Finalmente, para esta fecha sabemos cómo se ha comportado el virus en el Perú y en el mundo durante el primer pico de infección, y nos queda a todos la sensación y evidencia de que una nueva ola podría empeorar la situación. Esto nos lleva a pensar: ¿Cuál es la metodología más recomendada según la prevalencia de la enfermedad en un momento determinado?

\section{REFERENCIAS}

1. Loeffelholz MJ, Tang YW. Laboratory diagnosis of emerging human coronavirus infections-the state of the art Emerg Microbes Infect. [Internet] 2020 Dic; 9(1): 747-756 [Consultado 2020 Dic 10] doi: 10.1080/22221751.2020.1745095 https://pubmed.ncbi. nlm.nih.gov/32196430/ 
2. nterim Guidelines for COVID-19 Antibody Testing [Internet] Centers for Disease Control and Prevention [Consultado 2020 Dic 10] Disponible en: https://www. cdc.gov/coronavirus/2019-ncov/lab/resources/antibody-tests-guidelines.html

3. Wang H, Li X, Li T, Zhang S, Wang L, Wu X, et al. The genetic sequence, origin, and diagnosis of SARS-CoV-2. Eur J Clin Microbiol Infect Dis. [Internet] $2020 \mathrm{Sep}$ 39(9): 1629-1635 [Consultado 2020 Dic 10] doi: 10.1007/ s10096-020-03899-4

4. To KKW, Tsang OTY, Leung WS, Tam AR, Wu TC, Lung DC, et al. Temporal profiles of viral load in posterior oropharyngeal saliva samples and serum antibody responses during infection by SARS-CoV-2: an observational cohort study. Lancet Infect Dis. [Internet] 2020 May; 20(5): 56574 [Consultado 2020 Dic 10] Disponible en: https://www. thelancet.com/article/S1473-3099(20)30196-1/fulltext

5. Ferreira CE, Bonvehi PE, de la Torre JCG, Sáenz-Flor KV, Condino-Neto A. Algorithms for testing COVID-19 focused on use of RT-PCR and high-affinity serological testing: A consensus statement from a panel of Latin American experts. Int J Infect Dis. [Internet] 2020 Novi 103: 260-267 [Consultado 2020 Dic 13] doi: https://doi. org/10.1016/j.jijid.2020.11.173

6. Guio H. La "guerra" es contra nuestras limitaciones conceptuales que el virus ha desnudado. Revista Peruana de Ciencias de la Salud [Internet] 2020 Oct; 2(3): 131-4 [Consultado 2020 Dic 13] doi: http://doi.org/10.37711/ rpcs.2020.2.3.189

7. Hanson KE, Caliendo AM, Arias CA, Englund JA, Lee MJ, Loeb M, et al. Infectious Diseases Society of America Guidelines on the Diagnosis of Coronavirus Disease 2019. Clinical Infectious Diseases [Internet] 2020 Jun: 1-27 [Consultado 2020 Dic 13] doi: https://doi.org/10.1093/cid/ciaa760

8. COVID-19: consenso sobre el uso de pruebas diagnósticas para SARS-Cov-2 [Internet] Organización Panamericana de la Salud [Consultado 2020 Dic 13] Disponible en: https://covid19-evidence.paho.org/handle/20.500.12663/2351

9. Clinical management of severe acute respiratory infection (SARI) when COVID-19 disease is suspected [Internet] [Consultado 2020 Dic 13]. Disponible en: https:// www.who.int/docs/default-source/coronaviruse/clinical-management-of-novel-cov.pdf
10. D'Cruz RJ, Currier AW, Sampson VB. Laboratory Testing Methods for Novel Severe Acute Respiratory Syndrome-Coronavirus-2 (SARS-CoV-2). Front Cell Dev Biol [Internet] 2020 Jun; 8: 468 [Consultado 2020 Dic 13] doi: https://doi.org/10.3389/fcell.2020.00468

11. Interim Guidance for Antigen Testing for SARS-CoV-2 [Internet] Centers for Disease Control and Prevention [Consultado 2020 Dic 13] Disponible en: https://www. cdc.gov/coronavirus/2019-ncov/lab/resources/antigen-tests-guidelines.html

12. Bruning $A H L$, Leeflang MMG, Vos JMBW, Spijker R, De Jong MD, Wolthers KC, et al. Rapid tests for influenza, respiratory syncytial virus, and other respiratory viruses: A systematic review and meta-Analysis. Clin Infect Dis. [Internet] 2017 Sep; 65(6):1026-32 [Consultado 2020 Dic 14] doi: $10.1093 / \mathrm{cid} / \mathrm{cix} 461$.

13. Dinnes J, Deeks JJ, Adriano A, Berhane S, Davenport C, Dittrich $S$, et al. Rapid, point-of-care antigen and molecular-based tests for diagnosis of SARS-CoV-2 infection. Cochrane Database Syst Rev. [Internet] 2020 Aug; 2020(8):CD013705-CD013705 [Consultado 2020 Dic 13] doi: https://doi.org/10.1002/14651858.CD013705

14. Lambert-Niclot $S$, Cuffel A, Le Pape $S$, Vauloup-Fellous $C$, Morand-Joubert L, Roque-Afonso AM, et al. Evaluation of a rapid diagnostic assay for detection of sars-cov-2 antigen in nasopharyngeal swabs. Journal of Clinical Microbiology. American Society for Microbiology [Internet] 2020 Jul; 58(8): e00977-20 [Consultado 2020 Dic 13] doi: $10.1128 / J C M .00977-20$

15. Porte L, Legarraga P, Vollrath V, Aguilera X, Munita JM, Araos $R$, et al. Evaluation of a novel antigen-based rapid detection test for the diagnosis of SARS-CoV-2 in respiratory samples. Int J Infect Dis. [Internet] 2020 Oct; 99:328-33 [Consultado 2020 Dic 13] doi: 10.1016/j. ijid.2020.05.098

16. Zhao HJ, Lu XX, Deng Y Bin, Tang YJ, Lu JC. COVID-19: Asymptomatic carrier transmission is an underestimated problem. Epidemiol Infect. [Internet] 2020; 148: e116 [Consultado 2020 Dic 14] doi: 10.1017/ S0950268820001235.

17. Wikramaratna PS, Paton RS, Ghafari M, Lourenço J. Estimating the false-negative test probability of SARSCoV-2 by RT-PCR. MedRxiv En prensa. doi: https://doi. org/10.1101/2020.04.05.20053355 